\title{
Posterior and postero-lateral incidental durotomy during lumbar spine surgery: primary repair versus augmented primary repair
}

\author{
Mansour A. Makia, Ahmed Alawamry and Ahmad M. Elsharkawy ${ }^{*}$ (])
}

\begin{abstract}
Background: Incidental durotomy (ID) during lumbar spine surgery is a frequent complication of lumbar spine surgical procedures. Many surgical techniques were described in literature for repair of durotomy, however it is a matter of debate if one technique is a gold standard method of repair. Our study described two groups with posterior and postero-lateral ID that occurred during lumbar spine surgery: group A with 34 cases with a mean age of 49.85 years repaired by primary water tight closure using prolene or silk sutures, and group B with 34 cases with a mean age of 47.18 years treated with augmented primary repair (sutures augmented with a graft from lumbar fascia and tissue sealant "Fibrin glue"). Patients were evaluated for risk factors for durotomy, post-operative clinical outcome, and need for revision surgery.

Results: Eleven cases of group A and nine cases of group B had previous spine surgery. The dural tear was $<2 \mathrm{~cm}$ in $41.7 \%$ of group A and $83.3 \%$ of group B. Better outcome was achieved in 32 patients of group A and 30 patients of group B. Among our study cases 2 patients from group A and 4 patients from group B needed revision surgery due to CSF leak which failed to stop with conservative management and percutaneous blood patch.

Conclusions: Dural closure technique after ID does not seem to influence revision surgery rates due to cerebrospinal fluid (CSF) leakage and its complications. Durotomies that were immediately recognized and treated did not lead to any significant consequences.
\end{abstract}

Keywords: Incidental Durotomy, Revision surgery, Primary repair, Augmented primary repair, CSF leak, Lumbar spine surgery

\section{Background}

The incidence of incidental durotomy (ID) during the different lumbar spinal procedures was estimated between $1.6 \%-17.4 \%$ [31]. Previous studies suggested that ID can occur irrespective of a surgeon's abilities or experience [23]. Studies have also suggested that ID is associated with the age of the patient $[5,17]$, the type of procedure performed $[17,26,28]$, primary vs. revision surgery [12, $17,27,30]$, procedures with fixation and fusion [23], and the presence of pre-existing conditions such as ossified

\footnotetext{
*Correspondence: d.ahmad_elsharkawy@yahoo.com

Department of Neurosurgery, Zagazig University, P.O.BOX 44512, Zagazig, Egypt
}

posterior longitudinal ligament [12], diabetes, osteoporosis, arthritis [23] and ossification of the ligament flavum [8].

Many techniques were described for repair of durotomy including primary sutures with or without added augmentation like grafts or tissue sealants [3]. Both synthetic grafts and grafts from the patient as lumbar fascia, fat, or muscle grafts were described [15]. in some cases with anterior or far lateral durotomy primary watertight repair is not guaranteed, so repair with standalone grafts and tissue sealant was also described $[14,27]$. The poor outcome, longer hospital stay, longer immobilization, infection, and revision surgery are possible complications of poorly managed durotomy during 
the initial procedure, also minor postoperative complications, including headache, nausea, vomiting, neck pain, back pain, dizziness, diplopia, photophobia, tinnitus, and blurred vision can occur $[2,7]$.

In the present study, we aim to evaluate two techniques of ID repair and whether the method of repair can affect post-operative complications or not.

\section{Methods}

This prospective follow-up study was conducted at the neurosurgery department, Zagazig University hospitals during the period from June 2017 to January 2020 after performing 704 different lumbar spine procedures including microdiscectomy, standard laminectomy with or without discectomy, and lumbar fixation for instability. Out of these surgeries, we studied 68 patients with posterior and postero-lateral unintended durotomy. we classified patients into two groups: Group A included 34 patients and were treated by primary repair using 5-zero prolene or silk with a round needle. Group B included also 34 patients who were treated as group A (Figs. 1, 2) but with the addition of lumbar fascia graft and tissue sealant (fibrin glue), what we called augmented primary repair. Patients' allocation to groups was a randomized process. Valsalva maneuver was performed by the anesthetist to ensure watertight dural closure. The decision to leave a subfascial drain was left to surgeon experience and intraoperative requirements. All cases with anterior and far lateral durotomy that couldn't be closed primarily were excluded from our study. The important variables that had been analyzed were the patients' age, sex, and history of previous lumbar surgery, the primary diagnosis, details of the surgical procedure, details of the ID and its management, postoperative clinical evaluation, and follow-up.

The "Statistical Package for the Social Sciences" (SPSS) software (version 21) was used for data entry and data

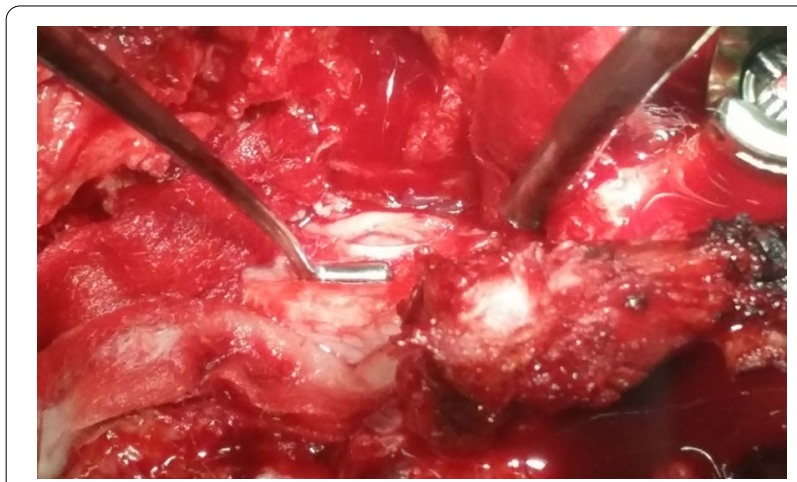

Fig. 1 Intra-operative photo of thecal sac showing $1 \mathrm{~cm}$ incidental dural tear

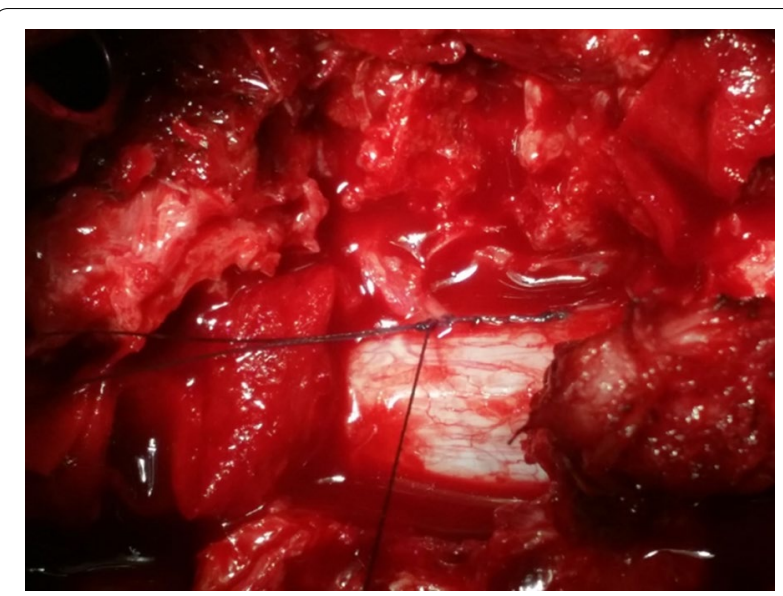

Fig. 2 Intra-operative photo of thecal sac showing complete simple closure of incidental dural tear using 5-0 silk suture

analysis. Qualitative data were represented as absolute frequency and percentage while quantitative data were represented as mean \pm standard deviation (SD) To measure the association between qualitative data, the Chi-square test, and Fisher exact test were used when appropriate. Mann Whitney test and independent sample t-test were used to compare continuous variables between two groups for non-parametric and parametric data respectively. P-value of $<0.05$ was considered significant. P-value $\leq 0.001$ was considered as statistically highly significant.

\section{Results}

Regarding the two-group design, there is a statistically non-significant difference between the studied groups regarding age, gender, body mass index (BMI), previous surgery, or the number of operated levels (Table 1). Dural tear less than $2 \mathrm{~cm}$ was more common (42 cases) compared to larger than $2 \mathrm{~cm}$ (26 cases). There is a statistically non-significant difference $(\mathrm{P}$ value $>0.05$ between the studied groups regarding the extent of the dural tear and postoperative immobilization (Table 2). Good clinical outcome was noted in 32 and 30 cases in group A and group B respectively. Mean Length of hospital stay was 7.94 days in group A compared to 9.56 days in group B. Mean time of immobilization or bed rest was 4.5 days in group A compared to 5.12 days in group B. CSF leak was found in 3 cases in group B and 5 cases in group A. Further management with a blood patch was done for 4 patients in group $\mathrm{A}$ and 3 patients in group B. None of the patients required a lumbar drain insertion in either group to stop CSF leak. There is a statistically non-significant difference $(\mathrm{P}$ 
Table 1 Baseline characteristics of the studied groups

\begin{tabular}{|c|c|c|c|c|}
\hline \multirow[t]{2}{*}{ Characteristics } & $\begin{array}{l}\text { Primary } \\
\text { repair Group } \\
\text { (A) }\end{array}$ & $\begin{array}{l}\text { Augmented } \\
\text { repair Group } \\
\text { (B) }\end{array}$ & $x^{2}$ & $P$ \\
\hline & $N=34$ & $N=34$ & & \\
\hline \multicolumn{5}{|l|}{ Gender } \\
\hline Female & $9(26.5 \%)$ & $16(47.1 \%)$ & 3.1 & 0.078 \\
\hline Male & $25(73.5 \%)$ & $18(52.9 \%)$ & & \\
\hline \multicolumn{5}{|l|}{ Age } \\
\hline Mean $\pm S D$ & $49.85 \pm 9.27$ & $47.18 \pm 8.05$ & $\mathrm{t}(-1.171)$ & 0.208 \\
\hline \multicolumn{5}{|l|}{ BMI } \\
\hline Mean $\pm S D$ & $27.68 \pm 2.84$ & $26.75 \pm 2.27$ & $t(-1.486)$ & 0.142 \\
\hline \multicolumn{5}{|l|}{ Co morbidity } \\
\hline NAD & $13(38.2 \%)$ & $15(44.1 \%)$ & & \\
\hline Smoker & $13(38.2 \%)$ & $6(17.7 \%)$ & & \\
\hline Diabetes & $8(23.6 \%)$ & $13(38.2 \%)$ & 3.912 & 0.141 \\
\hline \multicolumn{5}{|l|}{ ASA } \\
\hline Mean \pm SD & $2.33 \pm 0.62$ & $2.49 \pm 0.51$ & $t(1.12)$ & 0.267 \\
\hline \multicolumn{5}{|c|}{ Previous surgery } \\
\hline No & $23(67.6 \%)$ & $25(73.5 \%)$ & & \\
\hline Yes & $11(32.4 \%)$ & $9(26.5 \%)$ & 0.283 & 0.595 \\
\hline
\end{tabular}

$Z$ Mann Whitney test $t$ independent sample $t$-test $p>0.05$ is statistically nonsignificant

Table 2 operative variables of the studied groups

\begin{tabular}{|c|c|c|c|c|}
\hline & $\begin{array}{l}\text { Primary } \\
\text { repair Group } \\
\text { (A) }\end{array}$ & $\begin{array}{l}\text { Augmented } \\
\text { repair Group } \\
\text { (B) }\end{array}$ & $x^{2}$ & $P$ \\
\hline & $N=34$ & $N=34$ & & \\
\hline \multicolumn{5}{|c|}{ No of operated levels } \\
\hline Mean $\pm S D$ & $2.32 \pm 0.88$ & $1.97 \pm 1.14$ & Z (-1.633) & 0.102 \\
\hline \multicolumn{5}{|c|}{ Extent of dural tear } \\
\hline $0-2 \mathrm{~cm}$ & $14(41.7 \%)$ & $28(82.3 \%)$ & & \\
\hline$>2 \mathrm{~cm}$ & $20(58.3 \%)$ & $6(17.7 \%)$ & 12.205 & $<0.001^{* *}$ \\
\hline \multicolumn{5}{|c|}{ Post-op immobilization } \\
\hline Mean \pm SD & $1.469 \pm 0.57$ & $1.5 \pm 0.3$ & $t(-0.281)$ & 0.78 \\
\hline
\end{tabular}

"T independent sample t-test $p<0.05$ is statistically significant

value $>0.05$ ) between the two studied groups regarding the clinical outcome, duration of drain inserted, duration of bed rest, need for revision surgery, further management, or post-op complications, however, there was statistically significant longer hospital stay in group B (Table 3). Revision surgery was needed for 2 cases in group A and 4 cases in group B after an initial period of conservative management. Revision surgery had a statistically significant relation to the number of operated levels, increased duration of hospital stay, longer
Table 3 Primary and secondary outcome of the studied groups

\begin{tabular}{|c|c|c|c|c|}
\hline & $\begin{array}{l}\text { Primary repair } \\
\text { Group (A) }\end{array}$ & $\begin{array}{l}\text { Augmented } \\
\text { repair Group (B) }\end{array}$ & $x^{2}$ & $P$ \\
\hline & $N=34$ & $N=34$ & & \\
\hline \multicolumn{5}{|c|}{ Clinical outcome } \\
\hline Better & $32(94.1 \%)$ & $30(88.2 \%)$ & & \\
\hline Worse & $2(5.9 \%)$ & $4(11.8 \%)$ & Fisher & 0.673 \\
\hline \multicolumn{5}{|c|}{ Length of hospital stay (days) } \\
\hline Mean \pm SD & $7.94 \pm 6.46$ & $9.56 \pm 8.05$ & Z (-2.173) & $0.03^{*}$ \\
\hline \multicolumn{5}{|c|}{ Days of drains } \\
\hline Mean \pm SD & $4.38 \pm 0.49$ & $4.62 \pm 1.16$ & $t(1.092)$ & 0.281 \\
\hline \multicolumn{5}{|c|}{ Days of bed rest } \\
\hline Mean \pm SD & $4.5 \pm 0.79$ & $5.12 \pm 1.79$ & $t(1.843)$ & 0.072 \\
\hline \multicolumn{5}{|c|}{ Revision surgery } \\
\hline No & $32(94.1 \%)$ & $30(88.2 \%)$ & & \\
\hline Yes & $2(5.9 \%)$ & $4(11.8 \%)$ & Fisher & 0.673 \\
\hline \multicolumn{5}{|c|}{ Further management } \\
\hline Blood patch & $4(13.6 \%)$ & $3(8.8 \%)$ & Fisher & 0.476 \\
\hline \multicolumn{5}{|c|}{ Complications } \\
\hline No & $29(85.3 \%)$ & $27(91.2 \%)$ & & \\
\hline CSF leakage & $5(14.7 \%)$ & $3(8.8 \%)$ & Fisher & 0.709 \\
\hline
\end{tabular}

${ }^{*} T$ independent sample t-test $p<0.05$ is statistically significant

post-op bed rest, post-op complications, and longer duration of a subfacial drain (Table 4).

\section{Discussion}

Direct trauma to the dural sac, excessive nerve root traction, and misdirected pedicle screws during instrumentation are causes of ID [2]. Symptoms like postural headache, vertigo, nausea, tinnitus, and blurred vision $[6,19,21]$ may occur due to a prolonged CSF leakage, as a result of decreased CSF pressure [11, 29]. In some rare cases, more severe complications such as the development of pseudomeningocele $[19,25]$, arachnoiditis, meningitis [30], or cerebellar hematomas [4, 9, 20, 22] can occur. In our study, none of the patients experienced any kind of severe complications. Incidence of ID can be minimized by fine surgical techniques however can't be completely prevented [7].

Maria Kamenova et al. studied three techniques for the intra-operative closure of durotomy: Primary sutures, non-sutured grafts, and primary sutures with synthetic or muscle and fascia grafts. Results on 64 patients showed no statistical difference in either revision surgery or hospital stay between the three techniques [18]. Wang et al. described a repair using 4-0 or 5-0 silk running locked sutures with on top Gelfoam (Johnson \& Johnson, Gargrave, United Kingdom) with subfascial drain and tight multi-layers closure [30]. 
Table 4 Relation between pre, postoperative variables and the need for revision surgery among studied groups:

\begin{tabular}{|c|c|c|c|c|}
\hline & \multicolumn{2}{|c|}{ Revision surgery } & \multirow[t]{2}{*}{$x^{2}$} & \multirow[t]{2}{*}{$P$} \\
\hline & No $(n=62)$ & Yes $(n=6)$ & & \\
\hline \multicolumn{5}{|l|}{ Gender } \\
\hline Female & $21(33.9 \%)$ & $4(66.7 \%)$ & & \\
\hline Male & $41(66.1 \%)$ & $2(33.3 \%)$ & Fisher & 0.183 \\
\hline \multicolumn{5}{|l|}{ Age } \\
\hline Mean \pm SD & $48.98 \pm 8.55$ & $43.67 \pm 9.87$ & $t(1.437)$ & 0.155 \\
\hline \multicolumn{5}{|l|}{ BMI } \\
\hline Mean \pm SD & $27.36 \pm 2.54$ & $25.67 \pm 2.84$ & $t(1.546)$ & 0.127 \\
\hline \multicolumn{5}{|c|}{ Co morbidity } \\
\hline NAD & $26(41.9 \%)$ & $2(33.3 \%)$ & & \\
\hline Smoker & $19(30.7 \%)$ & $0(0 \%)$ & & \\
\hline Diabetes & $17(27.4 \%)$ & $4(66.7 \%)$ & 4.666 & 0.097 \\
\hline \multicolumn{5}{|l|}{ ASA: } \\
\hline Mean \pm SD & $2.39 \pm 0.51$ & $2.67 \pm 1.03$ & $t(-0.648)$ & 0.544 \\
\hline \multicolumn{5}{|c|}{ Previous surgery } \\
\hline No & $42(67.7 \%)$ & $6(100 \%)$ & & \\
\hline Yes & $20(32.3 \%)$ & $0(0 \%)$ & Fisher & 0.169 \\
\hline \multicolumn{5}{|c|}{ No of operated levels } \\
\hline Mean \pm SD & $2.23 \pm 1.03$ & $1.33 \pm 0.52$ & $\mathrm{t}(3.592)$ & $0.005^{*}$ \\
\hline \multicolumn{5}{|c|}{ Extent of dural tear } \\
\hline $0-2 \mathrm{~cm}$ & $36(58.1 \%)$ & $6(100 \%)$ & & \\
\hline$>2 \mathrm{~cm}$ & $26(41.9 \%)$ & $0(0 \%)$ & Fisher & 0.075 \\
\hline \multicolumn{5}{|c|}{ Post-op immobilization } \\
\hline Mean \pm SD & $1.51 \pm 0.47$ & $1.33 \pm 0.26$ & 0.901 & 0.371 \\
\hline \multicolumn{5}{|c|}{ Clinical outcome } \\
\hline Better & $62(100 \%)$ & $0(0 \%)$ & & \\
\hline Worse & $0(0 \%)$ & $6(100 \%)$ & Fisher & $<0.001^{*}$ \\
\hline \multicolumn{5}{|c|}{ Length of hospital stay (days) } \\
\hline Mean \pm SD & $6.53 \pm 1.28$ & $31.67 \pm 1.03$ & -46.66 & $<0.001^{* *}$ \\
\hline \multicolumn{5}{|c|}{ Days of drains } \\
\hline Mean \pm SD & $4.32 \pm 0.65$ & $6.33 \pm 1.03$ & -4.681 & $0.004^{*}$ \\
\hline \multicolumn{5}{|c|}{ Days of bed rest } \\
\hline Mean \pm SD & $4.48 \pm 0.87$ & $8.33 \pm 1.16$ & -10.309 & $<0.001^{* *}$ \\
\hline \multicolumn{5}{|c|}{ Complications } \\
\hline No & $56(90.3 \%)$ & $6(100 \%)$ & & \\
\hline CSF leakage & $6(9.7 \%)$ & $0(0 \%)$ & Fisher & $>0.999$ \\
\hline
\end{tabular}

${ }^{* *} P \leq 0.001$ is statistically highly significant

D. G. Anderson and V. Popov described their technique in the closure of incidental durotomy in 56 patients using augmented primary closure with synthetic grafts such as collagen matrix (Duragen Plus; Integra Life sciences Corp, Plainsboro, New Jersey). After primary closure with interrupted sutures, the needle is left attached to some sutures so after the primary closures, those needles are used again to fix the duragen on the suture line. They had zero postoperative CSF leak and zero revision surgery in patients treated in this way [1].
Eismont et al. recommended fascial graft secured by interrupted sutures in the treatment of larger dural defects, while smaller dural tears should be closed in watertight fashion with on top fat graft [7]. Using an in vitro hydrostatic calf spine model, Dafford et al. compared using 5-0 surgilon and 6-0 prolene suture in the repair of dural tear, $6-0$ prolene achieved a better watertight closure. Fibrin sealant improved the watertight closure if not achieved with primary repair. leakage may result from the needle holes around sutures. 
There was a $38 \%$ reduction in leak with fibrin glue; with no statistical difference in using any type of tissue sealants [6].

In our study, we performed closure of dural tear using 5-0 prolene or silk continuous suture with a locked technique using a round needle in all patients. However in group B after primary closure we used facial or muscle graft fixed to the dura either by using the 5-0 suture or with added fibrin glue to ensure tight closure followed by tight multi-layer wound closure. No statistically significant difference was noted between both groups regarding post-operative immobilization, clinical outcome, and postoperative complications, although the duration of post-op hospital stay was statistically longer in patients with augmented primary repair. Neural tissue preservation and handling during the process of repair are the keys to good clinical outcome and function [24]. A tight fascial layer closure decreases the incidence of CSF leak through the surgical wound. A Valsalva maneuver at the end of the procedure confirms obtaining a watertight closure [16].

The recommendation of bed rest was variable between no bed rest, short to mid-term bed rest over 24 to $48 \mathrm{~h}$. [10] In our study, the duration of bed rest was $4.5 \pm 0.79$ days in group A (primary repair) and $5.12 \pm 1.79$ days in group B (augmented primary repair).

A duro-cutaneous fistula may result after insertion of sub facial drain [7]. however, in other studies [3, 13, $30]$, the use of drain is advocated on the procedure and was used in most cases. A subarachnoid drain can be an alternative for the treatment of postoperative CSF leak or chronic pseudomeningocele [7]. In this study, subfacial drain insertion was left to the surgeon experience and intra-operative circumstances such as length of dural tear, quality of dural closure, and the result of intra-operative Valsalva maneuver by the anesthetist.

In our study, after the management of ID, most of the patients $82.4 \%$ (56 of 68 patients) had an uneventful postoperative period, while $17.6 \%$ (12 of 68 patients) had postoperative complications in the form of superficial wound infection alone in 2 patients in group A (primary repair), CSF leakage alone in 3 patients in group A (primary repair) and 3 in group B (augmented primary repair) (Table 3 ). Only $5.9 \%$ of group A (2 of 34 patients) and $11.8 \%$ of group B (4 of 34 patients) had persistent CSF leak and wound dehiscence that was surgically managed after 2 weeks from the primary surgery. In their study, Wang et al. had a $2.3 \%$ reoperation rate ( 2 of 88 patients; both were revision cases). Similarly, Camissa et al. [3] had a reoperation rate of $9.1 \%$ (6 of 66 patients). In our study, $8.8 \%$ (6 of the 68 durotomy cases in our study) required re-exploration and repair of the defect.

\section{Limitations of the study}

We didn't have a group of repairing ID with synthetic graft as a standalone or adjuvant repair. We did not study the surgeon experience as a factor in causing the OR repairing ID. We didn't study anterior or lateral ID when primary closure is not guaranteed.

\section{Conclusion}

Augmentation of primary water-tight closure of ID using either fascial, muscle grafts, or using tissue sealant doesn't add more protection to primary water-tight closure and should only be kept to dural defects that seems intraoperative to be inadequately closed with sutures only. Identification of ID and initiation of repair helped to decrease post-operative complications.

\section{Abbreviations}

ID: Incidental durotomy; CSF: Cerebrospinal fluid; SPSS: Statistical Package for the Social Sciences; BMI: Body mass index.

\section{Acknowledgements}

We thank all participants and assistants in completing this work.

\section{Authors' contributions}

AE analysed and interpreted the patients' data regarding the risk factors, operative details and clinical outcome. MM performed clinical evaluation of patients of incidental durotomy, and helped in reviewing and editing the manuscript. AA performed statistical analysis of patients' data and helped in writing the manuscript. All authors read and approved the final manuscript.

\section{Funding}

Not applicable.

\section{Availability of data and materials}

The data sets generated during and/or analysed during the current study are available from the corresponding author on reasonable request.

\section{Declarations}

\section{Ethics approval and consent to participate}

The research protocol was approved by the ethical committee in the Faculty of Medicine Zagazig University in its monthly session and reference number is not applicable. An informed written consent was obtained from each patient.

\section{Consent for publication}

Not applicable.

\section{Competing interests}

The authors declare that they have no competing interests.

Received: 18 August 2020 Accepted: 11 August 2021

Published online: 08 November 2021

\section{References}

1. Anderson DG, Popov V. Repair of lumbar dural tears with a suture patch: retrospective single-surgeon case series. Am J Orthop (Belle Mead NJ). 2013;42(9):72-5.

2. Bosacco SJ, Gardner MJ, Guille JT. Evaluation and treatment of dural tears in lumbar spine surgery: a review. Clin Orthop. 2001;389:238-47.

3. Cammisa Jr FP, Girardi FP, Sangani PK, et al. Incidental durotomy in spine surgery. Spine 2000: 2663-7. 
4. Chadduck WM. Cerebellar haemorrhage complicating cervical laminectomy. Neurosurgery. 1981;9:185-9.

5. Clajus C, Stockhammer F, Rohde V. The intra and postoperative management of accidental durotomy in lumbar spine surgery: results of a German survey. Acta Neurochir (Wien). 2015;157:525-30.

6. Dafford, Erica \& Anderson, Paul. Comparison of dural repair techniques. The spine journal 2013;6:44.

7. Eismont FJ, Wiesel SW, Rothman RH. Treatment of dural tears associated with spinal surgery. J Bone Joint Surg Am. 1981:63(7):1132-6.

8. Epstein NE. The frequency and aetiology of intraoperative dural tears in 110 predominantly geriatric patients undergoing multilevel laminectomy with non-instrumented fusions. J Spinal Disord Tech. 2007;20(5):380-6.

9. Friedman JA, Ecker RD, Piepgras DG, Duke DA. Cerebellar haemorrhage after spinal surgery: report of two cases and literature review. Neurosurgery. 2002;50:1361-3.

10. Gautschi OP, Stienen MN, Smoll NR, Corniola MV, Tessitore E, Schaller K. Acta Neurochir (Wien). 2014;156(9):1813-20.

11. Guerin P, El Fegoun AB, Obeid I, Gille O, Lelong L, Luc S, et al. Incidental durotomy during spine surgery: incidence, management and complications A retrospective review. Injury. 2012:43:397-401.

12. Hannallah $D$, et al. Cerebrospinal fluid leaks following cervical spine surgery. J Bone Joint Surg Am. 2008;90(5):1101-5.

13. http://www.springerimages.com//mages/RSS/1-10.1007s 00586-009-1219-y-1

14. Jankowitz BT, et al. Effect of fibrin glue on the prevention of persistent cerebral spinal fluid leakage after incidental durotomy during lumbar spinal surgery. Eur Spine J. 2009:18(8):1169-74.

15. Kalevski SK, Peev NA, Haritonov DG. Incidental Dural Tears in lumbar decompressive surgery: incidence, causes, treatment, results. Asian J Neurosurg. 2010;5:54-9

16. Karaeminogullari O, Atalay B, Sahin O, et al. Remote cerebellar haemorrhage after a spinal surgery complicated by dural tear: case report and literature review. Neurosurgery 2005:57(1(Suppl, Jul)):E215.

17. Khan $\mathrm{MH}$, et al. Postoperative management protocol for incidental dural tears during degenerative lumbar spine surgery: a review of 3,183 consecutive degenerative lumbar cases. Spine (Phila Pa 1976). 2006; 31(22):2609-13.

18. Maria Kamenova, Severina Leu, Luigi Mariani, Stefan Schaeren, Jehuda Soleman: Management of Incidental Dural Tear during Lumbar Spine Surgery. To Suture or Not to Suture, From the Departments of Neurosurgery and Spine Surgery, University Hospital of Basel, Basel, Switzerland, Citation. World Neurosurg 2016;87:455-62.
19. Mayfield FH, Kurokawa K. Watertight closure of spinal dura mater. Technical note J Neurosurg. 1975;43:639-40.

20. Mikawa Y, Watanabe R, Hino Y, Ishii R, Hirano K. Cerebellar haemorrhage complicating cervical durotomy and revision C1-C2 fusion. Spine (Phila Pa 1976) 1994:19:1169-71.

21. Mokri B. Spontaneous cerebrospinal fluid leaks: from intracranial hypotension to cerebrospinal fluid hypovolemia evolution of a concept. Mayo Clin Proc. 1999;74:1113-23.

22. Morandi X, Riffaud L, Carsin-Nicol B, Guegan Y. Intracerebral haemorrhage complicating cervical "hourglass" schwannoma removal. Case report J Neurosurg. 2001;94:150-3.

23. Pechlivanis I, et al. Perioperative complication rate of lumbar disc microsurgery depending on the surgeon's level of training. Cen Eur Neurosurg. 2009;70(3):137-42.

24. Saxler G, Kramer J, Barden B. The long term clinical sequelae of incidental durotomy in lumbar disc surgery. Spine. 2005;30:2298-302.

25. Stambough JL, Templin CR, Collins J. Subarachnoid drainage of an established or chronic pseudomeningocele. J Spinal Disord. 2000;13:39-41.

26. Stolke D, Sollmann WP, Seifert V. Intra- and postoperative complications in lumbar disc surgery. Spine (Phila Pa 1976) 1989:14(1):56-9.

27. Tafazal SI, Sell PJ. Incidental durotomy in lumbar spine surgery: incidence and management. Eur Spine J. 2005;14(3):287-90.

28. Teli $\mathrm{M}$, et al. Higher risk of dural tears and recurrent herniation with lumbar micro-endoscopic discectomy. Eur Spine J. 2012;19(3):443-50.

29. Vakharia SB, Thomas PS, Rosenbaum AE, Wasenko JJ, Fellows DG. Magnetic resonance imaging of cerebrospinal fluid leak and tamponade effect of blood patch in post-dural puncture headache. Anesth Analg. 1997;84:585-90.

30. Wang JC, Bohlman $\mathrm{HH}$, Riew DK. Dural tears secondary to operations on the lumbar spine: Management and results after a two-yearminimum follow-up of eighty-eight patients. J Bone Joint Surg [Am] 1998:80:1728-32.

31. Williams BJ, Sansur TA, Smith JS, et al. Incidence of unintended durotomy in spine surgery based on 108.478 cases. Neurosurgery 2011;68:117-24.

\section{Publisher's Note}

Springer Nature remains neutral with regard to jurisdictional claims in published maps and institutional affiliations.

\section{Submit your manuscript to a SpringerOpen ${ }^{\circ}$ journal and benefit from:}

- Convenient online submission

- Rigorous peer review

- Open access: articles freely available online

- High visibility within the field

- Retaining the copyright to your article

Submit your next manuscript at $\boldsymbol{\nabla}$ springeropen.com 